\title{
A novel IGnT allele responsible for the adult i phenotype
}

\author{
Marie Lin, Min-Ju Hou, and Lung-Chih Yu
}

BACKGROUND: The adult i phenotype has been characterized as the presence of a very low level of I antigen but a high quantity of I antigen on red blood cells (RBCs). It has been noted that this rare phenotype is partially associated with congenital cataracts. It has been demonstrated that the human I locus expresses three $I G n T$ forms, IGnTA, IGnTB, and IGnTC, and that the IGnTC gene is responsible for the I antigen expression on RBCs. This report describes molecular genetic analysis of a Taiwanese person with the adult i phenotype but without congenital cataracts.

STUDY DESIGN AND METHODS: The five exon regions of the IGnT gene of the adult i individual were amplified by polymerase chain reaction (PCR) and cloned, and the sequences were determined. The activity of the IGnT enzyme expressed from the mutant IGnTC gene identified in this i adult was analyzed.

RESULTS: The presented adult i individual possesses wild-type IGnTA and IGnTB genes but a mutant IGnTC gene with a 243T>A nucleotide substitution, which predicts an amino acid alteration of Asn81Lys. PCRrestriction fragment length polymorphism analysis has been used to show that this $I G n T C^{\star} 243 A$ allele is uncommon in the general Taiwanese population. The activity of the IGnT enzyme expressed from the mutant $I G n T C^{\star} 243 A$ gene was significantly reduced when compared with that expressed from the wild-type IGnTC gene.

CONCLUSION: A novel IGnTC allele with a 243T>A missense mutation was demonstrated in our adult $\mathrm{i}$ Taiwanese without congenital cataracts. The molecular basis revealed for this adult i case agrees with the proposed molecular genetic mechanism, accounting for the partial association of the adult i phenotype with congenital cataracts.
7 he blood group I and i antigens were first detected on human red blood cells (RBCs) by cold agglutinating autoantibodies. ${ }^{1-8}$ Their expressions were found to have a reciprocal relationship and to be developmentally regulated. Adult human RBCs fully express I antigen, with only a few i antigens, whereas the $\mathrm{i}$ antigen is predominately present on fetal and neonatal RBCs. After birth, the quantity of I antigen gradually increases as the level of $i$ antigen decreases, until the normal Ii status of adult RBCs is reached after about 18 months of life. ${ }^{5,9}$ Like ABH antigens, the Ii are also referred to as histo-blood group antigens ${ }^{10}$ because they are not just detected on RBCs, but are known to also be present on the surface of most human cells and on soluble glycoproteins in various body fluids, including milk, ${ }^{11}$ plasma, ${ }^{12}$ saliva, ${ }^{12}$ amniotic fluid, ovarian cyst fluid, and urine. ${ }^{7,8}$ The $\mathrm{i}$ and I antigens have been characterized as linear and branched repeats of the $N$-acetyllactosamine carbohydrate structures, Gal $\beta 1-4 \mathrm{GlcNAc} \beta 1-3 \mathrm{Gal} \beta 1-$ 4GlcNAc-R and Gal $\beta 1-4$ GlcNAc $\beta 1-3(G a l \beta 1-4 G l c N A c \beta 1-$ 6)Gal $\beta 1-4 G l c N A c-R$, respectively, carried on glycolipids and glycoproteins. ${ }^{13-15}$ The $N$-acetyllactosamine repeats are synthesized by the sequential action of $\beta$-1,3- $N$-acetylglucosaminyltransferase and $\beta$-1,4-galactosyltransferase. Conversion of i into an I antigenic structure requires the enzyme activity of I-branching $\beta$-1,6- $N$-acetylglucosaminyltransferase (I $\beta 6$ GlcNAcT). ${ }^{14,16,17}$

ABBREVIATION: I $\beta 6$ GlcNAcT = I-branching $\beta-1,6-N-$ acetylglucosaminyltransferase.

From the Transfusion Medicine Laboratory, Mackay Memorial Hospital, Taipei; the Institute of Biochemical Sciences, National Taiwan University, Taipei; and the Institute of Biological Chemistry, Academia Sinica, Taipei, Taiwan.

Address reprint requests to: Lung-Chih $\mathrm{Yu}, \mathrm{PhD}$, the Institute of Biochemical Sciences, National Taiwan University, PO Box 23106, Taipei 106, Taiwan; e-mail: yulc@ntu.edu.tw.

Supported in part by Grant NSC 94-2627-H-195-001 (ML) and Grant NSC 94-2320-B-002-088 (LCY) from the National Science Council, Taiwan.

Received for publication December 22, 2005; revision received April 8, 2006, and accepted April 12, 2006.

doi: 10.1111/j.1537-2995.2006.01006.x

TRANSFUSION 2006;46:1982-1987. 
Most of the adult RBCs abundantly express I antigen; however, in a small percentage of individuals, the RBCs are rich in the $\mathrm{i}$ antigen and very low level in $\mathrm{I}^{4,5,9}$ This phenotype is called the adult i phenotype and is believed to result from lack of I-branching transferase activity. ${ }^{15,16}$ The frequency of the adult i phenotype is very low, with only a few occurrences in thousands or tens of thousands. ${ }^{\text {? }}$ In spite of its rareness, however, the adult i phenotype has attracted considerable attention because it appears to be partially associated with congenital cataracts. This association was first demonstrated in Japanese $\mathrm{e}^{18-20}$ and later also in three Taiwanese pedigrees. ${ }^{21,22}$ The association of the two traits appears strong in these two populations, as 29 of the 31 Japanese with the adult i phenotype and all 5 adult i members in the 3 Taiwanese families have congenital cataracts. The association, however, does not seem to be as pronounced in white populations, with only a few cases formally reported as having both the adult i phenotype and congenital cataracts. ${ }^{23-25}$

In 1993, Bierhuizen and colleagues ${ }^{26}$ first identified the cDNA encoding the I $\beta 6$ GlcNAcT through an expression cloning strategy. The gene, located on chromosome $6 \mathrm{p} 24$, is designated IGnT (recognized by the HUGO Gene Nomenclature Committee as GCNT2) ${ }^{27,28}$ In 2003, both our research team ${ }^{29}$ and Inaba and coworkers ${ }^{30}$ expanded the complexity of the human IGnT locus and demonstrated that three $I G n T$ forms, which have different exon 1, but identical exon 2 and exon 3 , coding regions, are expressed from the IGnT locus through utilization of alternative promoters (Fig. 1). The three IGnT transcripts, designated IGnTA, IGnTB, and IGnTC, encode three functional I $\beta 6$ GlcNAcT enzymes sharing 66 percent amino acid sequence identities and were found to have
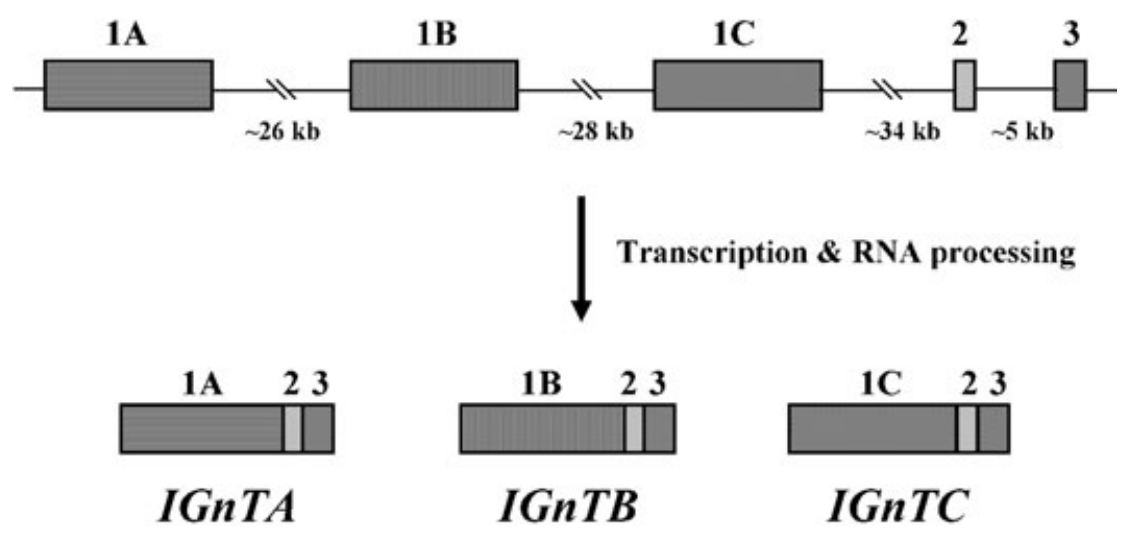

Fig. 1. Schematic representation of organization of the human $I$ locus and the structures of the expressed IGnT genes. Three IGnT transcripts, IGnTA, IGnTB, and IGnTC, which have different exon 1, but identical exon 2 and exon 3, coding regions, are expressed from the human $I$ locus (adapted from $\mathrm{Yu}$ et $\mathrm{al} .{ }^{29}$ ). The coding nucleotides of exons 1A, 1B, and 1C have 925, 919, and $925 \mathrm{bp}$, respectively, and the common exon 2 and exon 3 have respective coding nucleotides of 93 and $191 \mathrm{bp}$. It has been demonstrated that the IGnTC gene is responsible for the I antigen expression on RBCs. different expression profiles in different human tissues. Further, molecular genetic analysis of the two adult i groups, with or without congenital cataracts, was accomplished in our laboratory, ${ }^{29}$ with the results demonstrating that the IGnTC gene form is responsible for the blood group I antigen expression on RBCs. The most significant conclusion drawn in that article is of a molecular genetic mechanism accounting for the partial association of the adult i phenotype with congenital cataracts. It is proposed that the mutation event that occurs in the exon $1 \mathrm{C}$ region of the IGnTC gene may lead to the trait of adult i phenotype but not that of congenital cataracts, whereas the mutation that occurs in the common exon 2 to 3 region, and that consequently results in elimination of the activities of all three of the IGnT enzymes, may lead to both the studied traits.

To date, seven different mutations, including six nonsynonymous point mutations and one deletion, have been identified in the IGnT alleles of adult i individuals. ${ }^{22,29-31}$ Without exception, i adults without congenital association between the adult i phenotype and congenital cataracts is strong in Asian populations. Three Taiwanese pedigrees and one Japanese analog with both the adult $\mathrm{i}$ phenotype and congenital cataracts have been analyzed. ${ }^{22,29,30}$ Although adult i cases without cataracts have been identified in Japanese persons, ${ }^{19,20}$ molecular genetic analysis has never been performed for these individuals. In this study, a Taiwanese person with the adult i phenotype but without congenital cataracts was identified, and a novel IGnTC allele with a missense mutation of $243 \mathrm{~T}>\mathrm{A}$ is demonstrated.

\section{MATERIALS AND METHODS}

\section{Samples}

An individual with the adult i phenotype was identified with a standard hemagglutination test with the monoclonal anti-I antibody, which was a gift from Red Cross Blood Center of Osaka, Japan. This individual's daughter was typed as common I phenotype, and neither of the two family members have cataracts. Both the family members and the 58 randomly selected individuals analyzed in this study are Taiwanese, and informed consent was obtained from all participants before participation. Genomic DNA samples were prepared from their peripheral blood cells with a DNA blood mini kit (QIAamp, Qiagen 
GmbH, Hilden, Germany). Our use of human subjects was conducted under the tenets of the Helsinki protocol, and the program was approved by the Institutional Review Board at Mackay Memorial Hospital.

\section{Molecular cloning and sequence analysis for the IGnT gene}

The five exon regions of the $I G n T$ gene (exons 1A, 1B, 1C, 2 , and 3 ) were polymerase chain reaction (PCR)-amplified with the primer pairs as described previously. ${ }^{29}$ Fifty nanograms of genomic DNA and 5 pmol of each forward and reverse primer were combined in $12.5 \mu \mathrm{L}$ of PCR buffer containing $0.2 \mathrm{mmol}$ per $\mathrm{L}$ of dNTP and $0.625 \mathrm{U}$ of PfuUltra hotstart DNA polymerase (Stratagene, La Jolla, CA). The PCR products were cloned into the pCR4Blunt-TOPO vectors with a PCR cloning kit (Zero Blunt TOPO PCR cloning kit, Invitrogen, Carlsbad, CA). DNA sequences were determined with a cycle sequencing kit (BigDye Terminator, Applied Biosystems, Foster City, CA). Multiple clones from two batches of PCR products were sequenced to identify PCR errors from actual sequence polymorphisms.

\section{PCR-restriction fragment length polymorphism analysis}

The 243T $>$ A nucleotide substitution identified in the exon 1C region of the IGnT gene of the adult i case destroys a TfiI recognition sequence (GAWTC), and thus a PCR-based restriction fragment length polymorphism (RFLP) analysis was developed to demonstrate the mutation in the IGnTC gene. Fifty nanograms of genomic DNA and 5 pmol of each forward (ICF2, GCAAATTCAACCTCT CACACCGATC, 51 nucleotides upstream of the translational start ATG of IGnTC) and reverse (ICR6, TGAGTCAGTTCTCTAGGCGAGCAG, antisense sequence, 49 nucleotides downstream of exon 1C) primer were combined in $12.5 \mu \mathrm{L}$ of PCR buffer containing $0.2 \mathrm{mmol}$ per $\mathrm{L}$ dNTP and $0.25 \mathrm{U}$ of Taq polymerase (Promega, Madison, WI). The PCR program included 5 minutes at $94^{\circ} \mathrm{C}$ followed by 30 cycles of 30 seconds at $94^{\circ} \mathrm{C}, 30$ seconds at $62^{\circ} \mathrm{C}$, and 1 minute at $72^{\circ} \mathrm{C}$. The 1073-bp PCR products were subjected to digestion by TfiI restriction endonuclease and then analyzed by 1.5 percent agarose gel electrophoresis.

\section{Functional analysis of the enzyme encoded from the IGnTC cDNA}

Total RNA samples from the adult $i$ case and a common I individual were prepared from their peripheral blood cells with the QIAamp RNA blood mini kit (Qiagen). The firststrand cDNAs were primed with oligo(dT) primer and synthesized by reverse transcriptase (SuperScrip III, Invitrogen). The cDNA fragment encompassing the region of nucleotides 76 to 1206 , which encodes the amino acid residues 26 to 402, of the IGnTC gene was amplified by PCR as described previously ${ }^{29}$ and inserted into the mammalian expression vector pSecTaq2A (Invitrogen), which is designed for the secretion of the expressed protein into cell culture medium. The expression vectors bearing wild-type IGnTC and mutant IGnTC*243 A cDNAs were selected. The constructed and mock pSecTaq2A plasmids were prepared with a plasmid kit (EndoFree, Qiagen) for transfection. Expression of the constructed and mock plasmids in COS-7 cells, and the subsequent GlcNAcT assay were performed as has been described previously. ${ }^{22}$

\section{RESULTS}

\section{Missense mutation of 243T>A identified in IGnTC gene of the adult $\mathrm{i}$ individual}

The coding regions of the five exons of the IGnT gene of the adult $i$ individual were PCR-amplified and cloned, and the sequences were determined. Multiple clones from the exon 1A, 1B, 2, and 3 regions were analyzed, and all were found to have wild-type sequences; however, all five clones from the exon $1 \mathrm{C}$ region were found to possess a T-to-A nucleotide substitution at position 243. The wild-type sequences were also demonstrated from direct sequencing of the PCR products encompassing the respective exon 1A, 1B, 2, and 3 regions. Direct sequencing of the PCR product encompassing the exon 1C region demonstrated the homozygous state of the $243 \mathrm{~T}>\mathrm{A}$ substitution (Fig. 2). Taken together, these results suggest that the adult $\mathrm{i}$ individual is most likely to have wild-type IGnTA and IGnTB genes and be homozygous for the $243 \mathrm{~T}>\mathrm{A}$ mutation in the IGnTC gene. The possibility that the individual possesses only one chromosome with the mutant $I G n T C^{*} 243 \mathrm{~A}$ allele and another with the $I G n T$ locus deleted, however, cannot be totally excluded. The 243T $>$ A nucleotide change predicts an amino acid

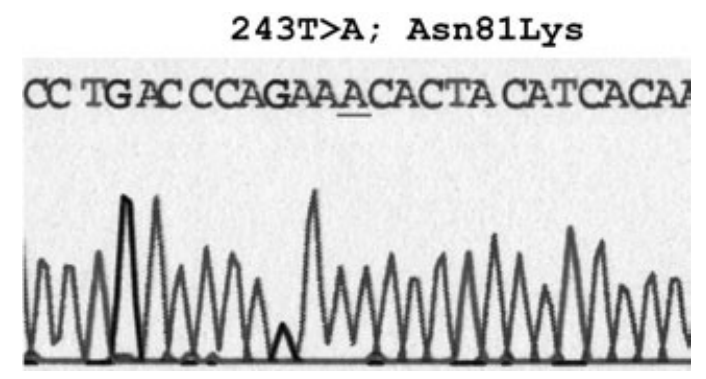

Fig. 2. Sequencing result of the exon $1 \mathrm{C}$ region of our adult $\mathrm{i}$ Taiwanese person. The exon $1 \mathrm{C}$ region of the IGnT gene of the adult $i$ individual was amplified by PCR and the sequence was analyzed by direct sequencing. The homozygous state of the T-to-A nucleotide change (underlined) at position 243 is demonstrated. The $243 \mathrm{~T}>\mathrm{A}$ substitution predicts the amino acid alteration of Asn81Lys in the encoded IGnTC enzyme. 
alteration of Asn to Lys at residue 81 in the encoded IGnTC enzyme.

The exon $1 \mathrm{C}$ region of the i adult's daughter, who was typed as the common I phenotype, was analyzed by direct sequencing after PCR amplification. The result showed heterozygous status of T and A nucleotides at position 243 (data not shown), suggesting that she is a heterozygote bearing the wild-type IGnTC and mutant IGnTC*243A alleles.

\section{The 243T $>$ A mutation in the IGnTC gene is uncommon in the general population}

The 243T $>$ A mutation identified in the IGnTC gene of the adult i case destroys a TfiI site and, thus, a PCR-RFLP analysis was developed to detect the mutation. The 1073-bp PCR product, which encompasses the exon $1 \mathrm{C}$ region and was amplified from the wild-type IGnTC allele, was cleaved into 585-, 316-, and 172-bp fragments by Tfi digestion, while that amplified from the mutant IGnTC allele with the $243 \mathrm{~T}>$ A mutation was cleaved into 585- and 488-bp fragments. The PCR-RFLP method was employed to inspect the incidence of the mutation in the general Taiwanese population. As shown in Fig. 3, the adult i case was homozygous for the 243T $>$ A mutation (Fig. 3, Lane 1) from PCR-RFLP analysis, whereas her daughter was a heterozygote with one IGnTC*243A allele (Fig. 3, Lane 2). None of the $I G n T C$ alleles of the 58 randomly selected

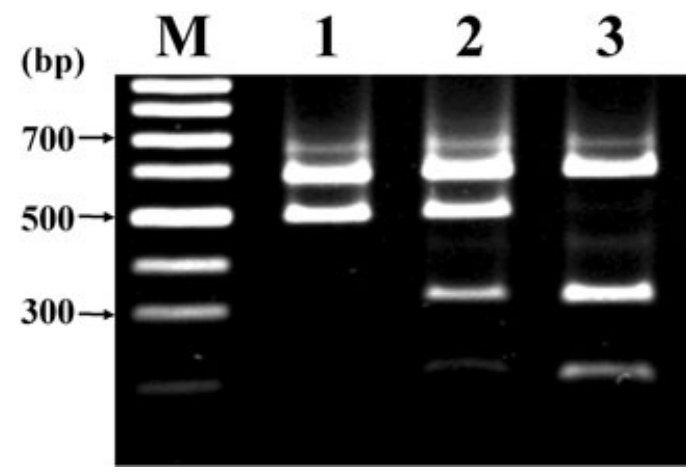

Fig. 3. PCR-RFLP analysis to demonstrate the IGnTC*243A allele. The 243T $>$ A mutation identified in the IGnTC gene of the adult $\mathrm{i}$ individual destroys a $\mathrm{T}$ fi I recognition sequence. The 1073-bp PCR product amplified from the exon 1C region with wild-type 243 T nucleotide was cleaved into 585-, 316-, and 172bp fragments by TfiI digestion, whereas that amplified from the mutant $I G n T C$ allele with the $243 T>$ A mutation was cleaved into 585- and 488-bp fragments. The TfiI-cleaved products were analyzed by 1.5 percent agarose gel electrophoresis. Samples from the adult $i$ individual (Lane 1) and her daughter (Lane 2), together with samples from 58 randomly selected individuals were subjected to PCR-RFLP analysis. One of the results obtained from the random individuals is shown (Lane 3). Lane $\mathrm{M}=$ molecular mass standards of the 100-bp ladder. individuals demonstrated the mutation (one of the results is shown in Fig. 3, Lane 3). This demonstrates that the $I G n T C$ allele with the $243 \mathrm{~T}>\mathrm{A}$ mutation is infrequent in the general population and agrees with the observed rarity of the adult i phenotype.

\section{Enzyme activity of the I $\beta 6$ GIcNAcTs encoded from the IGnTC*243 A cDNA}

The effect of the Asn81Lys change, resulting from the $243 \mathrm{~T}>\mathrm{A}$ mutation, on the enzyme activity of I $\beta 6 \mathrm{GlcNAcT}$ was tested. Table 1 lists the amounts of GlcNAc transferred to the acceptor substrate, LS-tetrasaccharide c (NeuNAc $\alpha 2-6 \mathrm{Gal} \beta 1-4 \mathrm{GlcNAc} \beta 1-3 \mathrm{Gal} \beta 1-4 \mathrm{Glc})$, from the donor substrate UDP-GlcNAc by the medium concentrates harvested from the cells transfected with the respective expression vectors. The enzyme expressed from the wild-type IGnTC cDNA displayed GlcNAc-transferring activity. In contrast, only residual activity was observed in the enzyme encoded from the mutant IGnTC*243A cDNA. This result indicates that the Asn81Lys alteration in IGnTC $\beta 6$ GlcNAcT significantly reduces the original GlcNAcT activity.

\section{DISCUSSION}

In this present study, a novel IGnTC gene with a $243 \mathrm{~T}>\mathrm{A}$ missense mutation was identified in a Taiwanese person with the adult i phenotype but without congenital cataracts. The mutation predicts the amino acid alteration of Asn81Lys in the encoded IGnTC enzyme. Molecular genetic analyses demonstrated that this $\mathrm{i}$ adult possesses wild-type $I G n T A$ and $I G n T B$ genes and is homozygous for the $I G n T C^{*} 243 A$ mutant allele. The population screening and enzyme function assay strongly suggest that this $I G n T C^{*} 243 A$ mutant allele is responsible for formation of the adult i phenotype.

It has been demonstrated that the human $I$ locus expresses three IGnT forms, IGnTA, IGnTB, and IGnTC, which have different exon 1, but identical exon 2 and exon 3 , coding regions. ${ }^{29,30}$ Based on the observed presence of normal quantities of I antigen in the milk, plasma,

TABLE 1. The GICNAcT activities of the enzymes encoded from the wild-type IGnTC and mutant IGnTC* 243A cDNAs*

\begin{tabular}{|c|c|c|c|}
\hline & Vector & IGnTC & IGnTC *243A \\
\hline GlcNAc transferred & $19.0 \pm 4.7$ & $76.4 \pm 22.6$ & $24.3 \pm 7.9$ \\
\hline
\end{tabular}

(pmol)

* The results of the mean and standard deviation of four tests are shown. Endogenous transfer of GlcNAc in the absence of acceptor substrate was corrected for each test. The amounts of the transferred GIcNAc in the vector control indicate the background levels of the assay. 
and saliva of i adults, ${ }^{32,33}$ it has been proposed that different I-branching enzymes may be responsible for the Iantigen synthesis in different tissues. The molecular genetics of the human $I$ locus and the differential expression profiles for the tissue-specific $I G n T$ gene forms support this proposition and provide a new view of the formation and expression of the I antigen. Our previous investigation of the two adult i groups (with and without cataracts) has shown that mutation in the IGnTC gene, leading to a defective IGnTC enzyme, is associated with the adult i phenotype, and it was demonstrated that $I G n T C$ is the only one of the three IGnT genes expressed in the reticulocytes. ${ }^{29}$ Further, it was demonstrated that $I G n T B$ is the only one of the three IGnT genes expressed in the human lens-epithelium cells. These results demonstrate that the exact gene form responsible for the expression of the blood group I antigen on RBCs is the IGnTC. More interestingly, the results obtained from our molecular analysis of the two adult i groups suggest a molecular genetic mechanism that accounts for the partial association between the adult i phenotype and congenital cataracts. A defect in IGnTC gene function leads to the adult $\mathrm{i}$ phenotype, whereas congenital cataracts occur in those i adults who have mutations in the common exon 2 to 3 region, which lead to defects in all three IGnT enzyme functions, but not in analogs who only have defects in the IGnTC form. This proposed molecular genetic mechanism suggests that a defect in the $I$ locus may lead directly to the development of congenital cataracts.

To date, seven different mutations, including six nonsynonymous point mutations and one deletion, have been identified in the $I G n T$ alleles of individuals with the adult i phenotype. The six point mutations include $505 \mathrm{G}>\mathrm{A}$ and $683 \mathrm{G}>\mathrm{A}$ (locating exon $1 \mathrm{C}$, identified in white persons without cataracts), ${ }^{29}$ 983G $>$ A (locating exon 2, identified in Arab persons with cataracts), ${ }^{31}$ 1006G $>\mathrm{A}$ (locating exon 2, identified in Japanese persons with cataracts), ${ }^{30} 1049 \mathrm{G}>\mathrm{A}$ (locating exon 3, identified in Japanese and Taiwanese persons with cataracts), ${ }^{22,29,30}$ and $1154 \mathrm{G}>\mathrm{A}$ (locating exon 3, identified in Taiwanese persons with cataracts). ${ }^{22,29}$ The deletion is a loss of a large chromosomal segment encompassing the region from exon $1 \mathrm{~B}$ through exon 3 (identified in Taiwanese persons with cataracts) ${ }^{22,29}$ These analyzed adult $i$ individuals belong to four different populations, with the revealed molecular genetic bases agreeing with the proposed molecular genetic mechanism accounting for the partial association between the adult i phenotype and congenital cataracts. To date, seven cases with the adult i phenotype but without congenital cataracts have been analyzed (six reported in our previous article ${ }^{29}$ and one analyzed in our laboratory subsequently), with all seven cases belonging to the white population. Carriage of the wild-type IGnTA and $I G n T B$ genes but double-dose mutation of $505 \mathrm{G}>\mathrm{A}$ or $683 \mathrm{G}>\mathrm{A}$ in the IGnTC gene was demonstrated in these individuals. The molecular genetic analysis of our adult $\mathrm{i}$ Taiwanese person reveals that a novel IGnTC mutant allele is responsible for the adult $\mathrm{i}$ phenotype and adds one more example of $i$ adults without congenital cataracts possessing wild-type IGnTA and IGnTB genes and a defective IGnTC gene only.

\section{REFERENCES}

1. Wiener AS, Unger LJ, Cohen L, Feldman J. Type-specific cold auto-antibodies as a cause of acquired hemolytic anemia and hemolytic transfusion reactions: biological test with bovine red cells. Ann Intern Med 1956;44:221-40.

2. Jenkins WJ, Marsh WL, Noades J, et al. The I antigen and antibody. Vox Sang 1960;5:97-106.

3. Tippett P, Noades J, Sanger R, et al. Further studies of the I antigen and antibody. Vox Sang 1960;5:107-21.

4. Marsh WL, Jenkins WJ. Anti-i: a new cold antibody. Nature (London) 1960;188:753.

5. Marsh WL. Anti-i: a cold antibody defining the Ii relationship in human red cells. Br J Haemat 1961;7:200-9.

6. Issitt PD, Anstee DJ. Applied blood group serology. Durham: Montgomery Scientific Publications; 1998.

7. Daniels G. Human blood groups. Oxford: Blackwell Science; 2002.

8. Reid ME, Lomas-Francis C. The blood group antigen factsbook. San Diego: Elsevier Ltd.; 2004.

9. Marsh WL, Nichols ME, Reid ME. The definition of two I antigen components. Vox Sang 1971;20:209-17.

10. Feizi T. Demonstration by monoclonal antibodies that carbohydrate structures of glycoproteins and glycolipids are onco-developmental antigens. Nature (London) 1985;314: 53-6.

11. Marsh WL, Nichols ME, Allen FH. Inhibition of anti-I sera by human milk. Vox Sang 1970;18:149-54.

12. Rouger P, Juszczak G, Doinel C, Salmon C. Relationship between I and $\mathrm{H}$ antigens. I. A study of the plasma and saliva of a normal population. Transfusion 1980;20:536-9.

13. Neimann H, Watanabe K, Hakomori S, Childs RA, Feizi T. Blood group i and I activities of 'lacto- $N$-norhexaosylceramide' and its analogues: the structural requirements for i-specificity. Biochem Biophys Res Commun 1978;81:1286-93.

14. Watanabe K, Hakomori S, Childs RA, Feizi T. Characterization of a blood group I-active ganglioside. J Biol Chem 1979;254:3221-8.

15. Koscielak J, Zdebska E, Wilczynska Z, Miller-Podraza H, Dzierzkowa-Borodej W. Immunochemistry of Ii-activity glycosphingolipids. Eur J Biochem 1979;96:331-7.

16. Fukuda M, Fukuda M, Hakomori S. Developmental change and genetic defect in the carbohydrate structure of band 3 glycoprotein of human erythrocyte membrane. J Biol Chem 1979;254:3700-3.

17. Piller F, Cartron JP. Biosynthesis of blood group I antigens. J Biol Chem 1984;259:13385-90. 
18. Yamaguchi H, Okubo Y, Tanaka M. A note on possible close linkage between the Ii blood locus and a congenital cataract locus. Proc Jpn Acad 1972;48:625-8.

19. Ogata H, Okubo Y, Akabane T. Phenotype i associated with congenital cataract in Japanese. Transfusion 1979;19:166-8.

20. Okubo Y, Yamaguchi H. I-negative phenotype and cataract. In: Program and abstracts of the XIX Congress of the International Society of Blood Transfusion; 1986; Sydney, Australia. p. 147.

21. Lin-Chu M, Broadberry RE, Okubo Y, Tanaka M. The i phenotype and congenital cataracts among Chinese in Taiwan. Transfusion 1991;31:676-7.

22. Yu LC, Twu YC, Chang CY, Lin M. Molecular basis of the adult I phenotype and the gene responsible for the expression of the human blood group I antigen. Blood 2001;98:3840-5.

23. Marsh WL, DePalma H. Association between the Ii blood group and congenital cataract. Transfusion 1982;22:337-8.

24. Macdonald EB, Douglas R, Harden PA. A Caucasian family with the i phenotype and congenital cataracts. Vox Sang 1983;44:322-5.

25. Page PL, Langevin S, Petersen RA, Kruskall MS. Reduced association between the Ii blood group and congenital cataracts in white patients. Am J Clin Pathol 1987;87:101-2.

26. Bierhuizen MF, Mattei MG, Fukuda M. Expression of the developmental I antigen by a cloned human cDNA encoding a member of a $\beta-1,6-N$-acetylglucosaminyltransferase gene family. Genes Dev 1993;7:468-78.

27. Yeh JC, Ong E, Fukuda M. Molecular cloning and expression of a novel $\beta$-1,6- $N$-acetylglucosaminyltransferase that forms core 2, core 4, and I branches. J Biol Chem 1999;274:3215-21.

28. Schwientek T, Nomoto M, Levery SB, et al. Control of O-glycan branch formation. J Biol Chem 1999;274:450412.

29. Yu LC, Twu YC, Chou ML, et al. The molecular genetics of the human $I$ locus and molecular background explain the partial association of the adult i phenotype with congenital cataracts. Blood 2003;101:2081-8.

30. Inaba $\mathrm{N}$, Hiruma $\mathrm{T}$, Togayachi $\mathrm{A}$, et al. A novel I-branching $\beta$-1,6- $N$-acetylglucosaminyltransferase involved in human blood group I antigen expression. Blood 2003;101:2870-6.

31. Pras E, Raz J, Yahalom V, et al. A nonsense mutation in the glucosaminyl( $N$-acetyl) transferase 2 gene (GCNT2): association with autosomal recessive congenital cataracts. Invest Ophthalmol Vis Sci 2004;45:1940-5.

32. Dzierzkowa-Borodej W, Seyfried H, Nichols M, Reid M, Marsh WL. The recognition of water-soluble I blood group substance. Vox Sang 1970;18:222-34.

33. Marsh WL, Jensen L, Decary F, Colledge K. Water-soluble I blood group substance in the secretions of $\mathrm{i}$ adults. Transfusion 1972;12:222-6. 